\title{
Using Magnetic Method for the Identification of Anomalies Due to Kimberlite Pipes, Luando Area, Bié, Angola
}

\author{
Gerson Itembo $^{1,2^{*}}$, João Baptista ${ }^{2}$, Ageu Cardoso ${ }^{2}$ \\ ${ }^{1}$ Department of Geosciences, Instituto Superior Politécnico de Tecnologias e Ciências (ISPTEC), Talatona, Luanda, Angola \\ ${ }^{2}$ Department of Geophysics, Universidade Agostinho Neto (UAN), Camama, Luanda, Angola \\ Email: *gersonitembo1@gmail.com
}

How to cite this paper: Itembo, G., Baptista, J. and Cardoso, A. (2020) Using Magnetic Method for the Identification of Anomalies Due to Kimberlite Pipes, Luando Area, Bié, Angola. International Journal of Geosciences, 11, 745-755.

https://doi.org/10.4236/ijg.2020.1111037

Received: September 15, 2020

Accepted: November 13, 2020

Published: November 16, 2020

Copyright $\odot 2020$ by author(s) and Scientific Research Publishing Inc. This work is licensed under the Creative Commons Attribution International License (CC BY 4.0).

http://creativecommons.org/licenses/by/4.0/

\begin{abstract}
One of the measurement geophysical methods to investigate kimberlite pipes is by using the magnetic method. The acquired field data in this study uses two proton-precession magnetometers for the mapping of magnetic anomalies due to kimberlites. Three different magnetic maps are obtained from the result of total magnetic field data processing on Oásis Montaj software programme. These maps include magnetic anomaly maps through statistical analyses, total magnetic field intensity map and map of the analytic signal. Based on the interpretation of these maps a structure is identified with SWW-NEE directions in which magnetic signatures that indicate the presence of kimberlite pipes are observed. As the interpretation of the magnetic anomalies is a complicated process due to their dipolar nature, the analytic signal is generated, where is possible to observe the typical shape of these anomalies.
\end{abstract}

\section{Keywords}

Near-Surface Geophysical Study, Magnetic Anomalies, Kimberlite Pipes,

Total Magnetic Field Anomalies, Analytic Signal Map

\section{Introduction}

The magnetic method is the oldest and has been one of the most widely used geophysical prospectings to study the Earth's subsurface since the method was first applied to find buried, iron ore deposits [1] [2]. It is an inexpensive tool largely used for mineral exploration purposes, even a regional tool for mapping the thickness of sedimentary basins, the geologic structure and buried crystalline 
rocks such as kimberlites [1]. Kimberlites can cause magnetic signatures and according to Brummer et al. (1992) they can be identified in aeromagnetic surveys, which are generally, a roughly circular anomaly [3].

It is known that kimberlites are ultrabasic igneous rocks, which normally occur as pipes, dikes or sills. Despite they are the major source of the world's diamonds [4]; only one percent of kimberlite pipes hold an economic deposit of diamonds [5]. Kimberlites occur primarily on Pre-Cambrian Cratons, formed particularly in Archaean age. In Angola, there are four cratonic areas that consist of shields that include: Mayombe Shield, Kassai Shield, Bangwela Shield and Angola Shield that is inside of Bié area [6] [7]. Many kimberlite pipes in Angola are located in platforms, in which the basement is overlaid by sedimentary rock.

Although there are many researches related to magnetic anomalies, the purposes of this paper are 1) to describe how magnetic method was employed in Luando area to map the total magnetic field and 2) to create a typical analytic signal map in the study area with a detailed interpretation. In order to achieve the purpose of this research, the study started with a brief overview of Luando area and an aeromagnetic survey was conducted in the study area, which allowed the understanding of the orientation of the main structures.

\section{Study Area}

Luando, the study area is located in North-East of Cuemba village, approximately bounded in the East by Longitude $18^{\circ} 01^{\prime}-19^{\circ} 15^{\prime}$ and in the South by Latitude $11^{\circ} 23^{\prime}-12^{\circ} 09^{\prime}$ (Figure 1 ). The topographic relief in this area is characterized by a

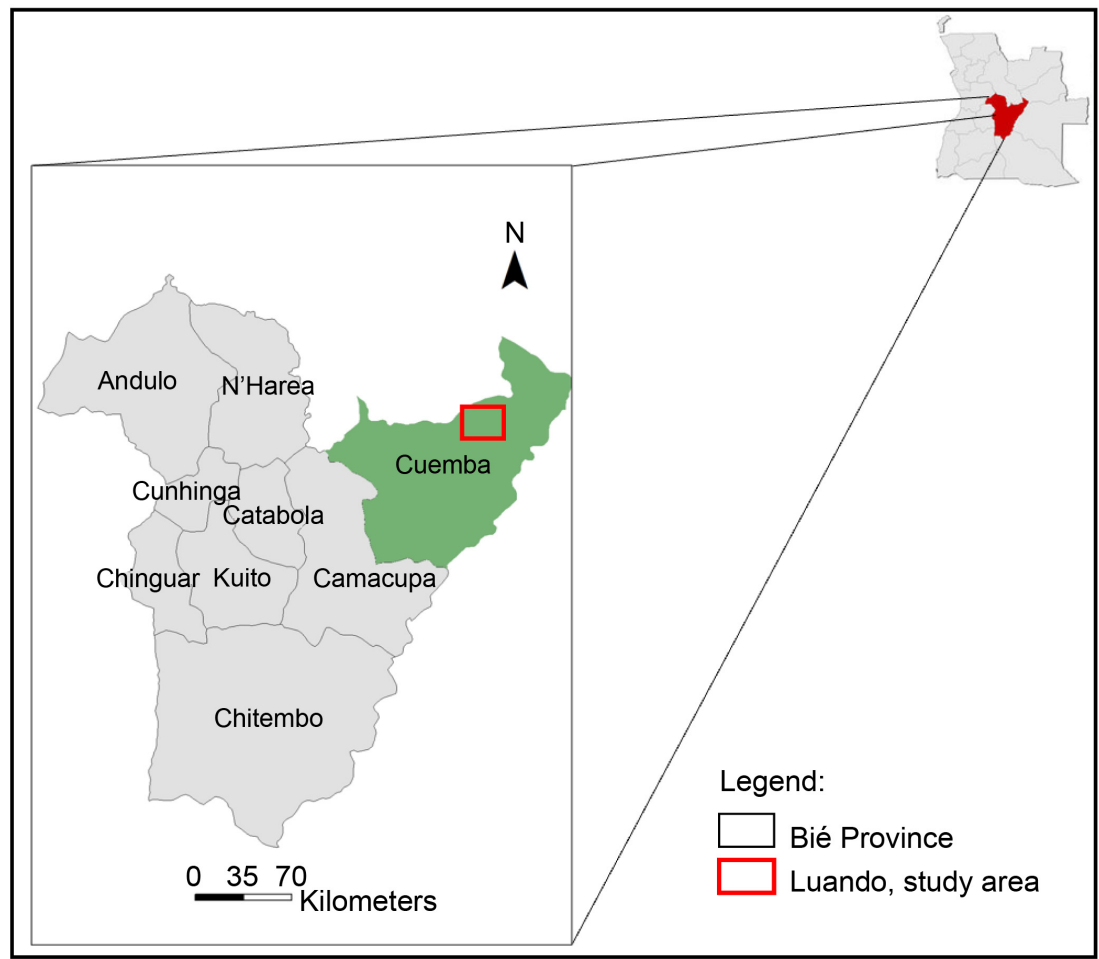

Figure 1. Luando, study area located in Cuemba, Bié province. 
plain with altitudes varying between 1100 and 1150 meters above sea level and another part of transition between plain and plateau with altitudes ranging from 1300 to 1400 meters above sea level. The area is relatively humid tropical region of the equatorial zone, which the relative humidity varies between $35 \%-40 \%$ in dry weather and $75 \%-80 \%$ in rainy weather, and it is also covered mainly by tall trees.

\section{Geologic Setting}

The degree of geologic setting of the area is insufficient. Studies and analyses made on photogeological maps in scale 1/1000,000, from Geological Institute of Angola, suggest that the survey area belongs to the regional geologic context with some rocks of the Archean Complex (metamorphic rock and intrusive rocks developed in the shield areas), Permian-Triassic (Cassanje group: consist of stoneware, clay and limestone), Cretaceous (Calonda formation: alluvial deposits and consist of polymeric conglomerates, siltstones, claystones, stoneware), Paleogene-Neogene (Kalahari group: sands with considerable contents of clays, silicified rocks, polymorphic sandstones and, conglomerates with variable colours.) and Quaternary deposits, which correspond to alluvial, alluvial-proluvial and diluvial-eluvial formations [6]. Tectonically, there are three major faults bounded the survey area, two with preferential directions northeast-southwest and the third fault with northwest-southeast directions, which is a deep continental and regional fault in the eastern area of Cassanje (Figure 2). All structures are predominantly normal faults in which the first two major faults formed a graben [8].

\section{Data Acquisition and Processing}

The survey location is shown in Figure 3. The field data is acquired using two

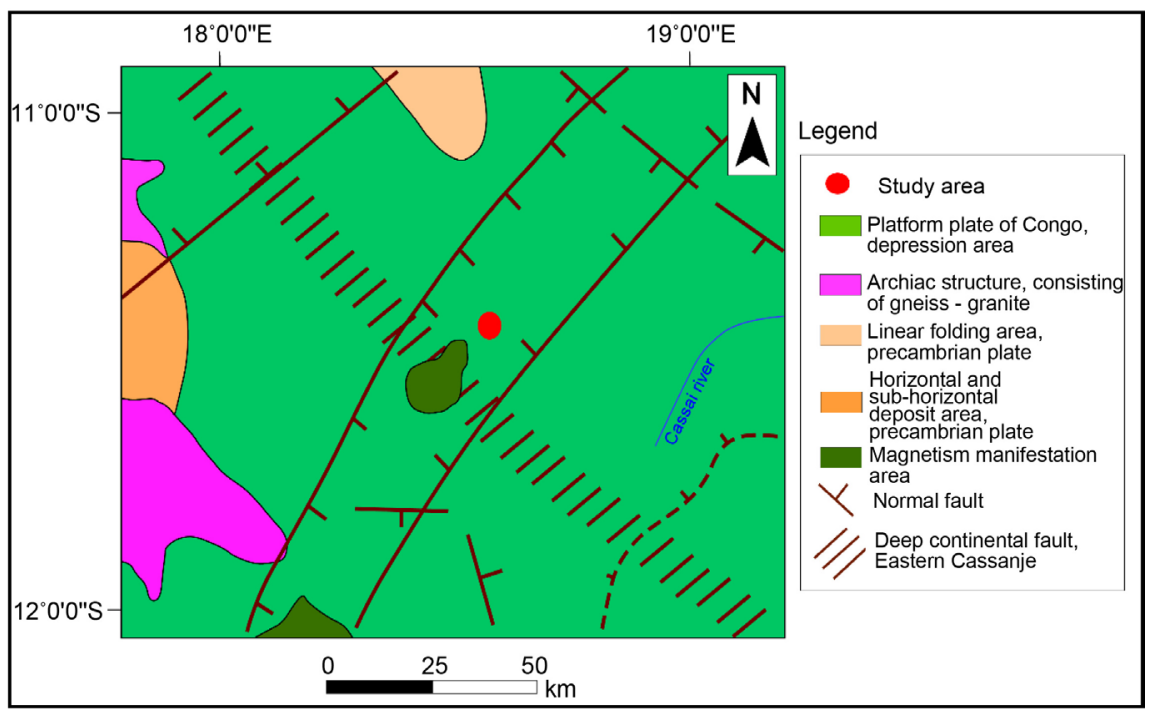

Figure 2. Schematic tectonic map showing regional geologic structures around Luando area. 


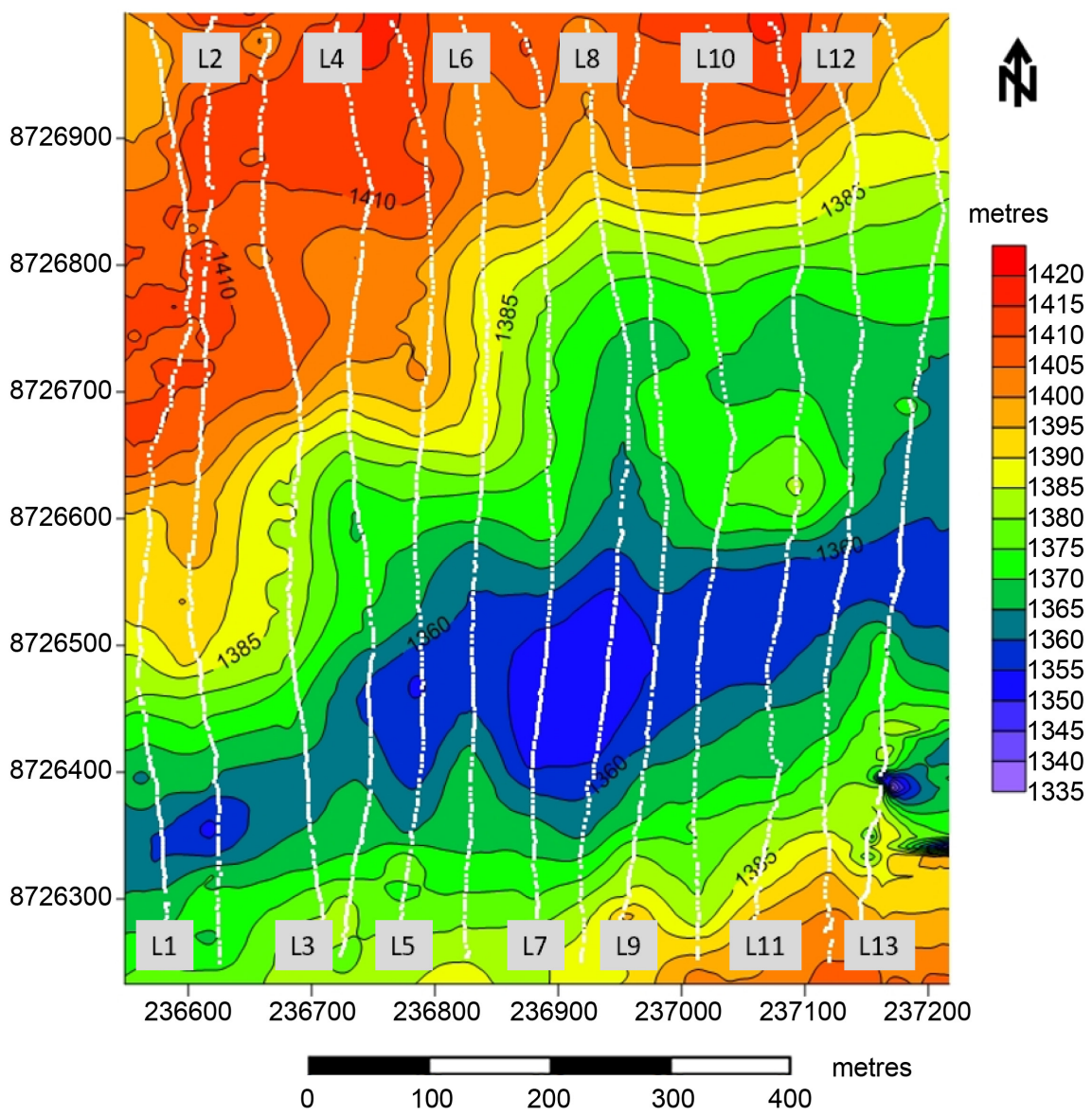

Figure 3. Spatial distribution map of acquired lines within the study area with elevation map.

proton-precession magnetometers, namely GSM-19 v7.0 Overhauser and Geotron model G5, which have an accuracy of the order of 0.1 to $1 \mathrm{nT}$. The GSM-19 v7.0 Overhauser was used as handheld instrument (Table 1), while Geotron model G5 was used as base station, measuring the diurnal variations. Observations of total magnetic field were made along 13 parallel lines spaced $50 \mathrm{~m}$ apart and each line has approximately one kilometre long. Data were gridded at a $5 \mathrm{~m}$ interval and oriented from south-north. To avoid several sources of interference in the acquisition of data, all operational precautions were taken regarding to objects with ferromagnetic properties.

The acquired data is processed using Oásis Montaj software programme from Geosoft Inc. This is powerful geophysical software used for reading, processing and interpretation of magnetic data. The processing of magnetic measurements started with the application of band pass filter for the removal of spikes (Figure 4 ) and to smooth the data. The resulting data from this process were corrected of the diurnal variation (Figure 5) and stored in a new window $(\mathrm{T})$, in which consists of subtracting, from the measured data by handheld instrument (rover), the measured data by the base station (BS). Therefore, the diurnal variation correction was defined using Equation (1); 
Table 1. Total magnetic intensity as a function of utm coordinates (datum WGS84) showing $42 \%$ of acquired data along the main line 6.

\begin{tabular}{|c|c|c|c|c|c|c|c|}
\hline $\mathbf{N}$ & $\mathbf{x}$ (UTM) & y (UTM) & $\begin{array}{l}\text { Total magnetic } \\
\text { field }(\mathrm{nT})\end{array}$ & $\mathbf{N}$ & X (UTM) & Y (UTM) & $\begin{array}{l}\text { Total magnetic } \\
\text { field (nT) }\end{array}$ \\
\hline 1 & 236821.08 & 8726241.88 & 31708.55 & 41 & 236827.04 & 8726424.95 & 31569.38 \\
\hline 2 & 236822.32 & 8726243.58 & 31708.6 & 42 & 236827.34 & 8726427.51 & 31562.4 \\
\hline 3 & 236820.91 & 8726249.9 & 31708.7 & 43 & 236827.51 & 8726429.97 & 31566.53 \\
\hline 4 & 236819.92 & 8726258.16 & 31708.86 & 44 & 236827.77 & 8726431.99 & 31582.58 \\
\hline 5 & 236819.48 & 8726266.19 & 31709.08 & 45 & 236828.03 & 8726435.11 & 31609.97 \\
\hline 6 & 236819.55 & 8726274.31 & 31709.38 & 46 & 236827.67 & 8726437.95 & 31646.72 \\
\hline 7 & 236819.74 & 8726279.85 & 31709.56 & 47 & 236827.41 & 8726441.78 & 31689.64 \\
\hline 8 & 236819.47 & 8726283.87 & 31709.77 & 48 & 236827.01 & 8726445.02 & 31734.75 \\
\hline 9 & 236819.34 & 8726287.26 & 31710 & 49 & 236826.8 & 8726448 & 31777.8 \\
\hline 10 & 236819.96 & 8726291.66 & 31710.26 & 50 & 236826.54 & 8726451.87 & 31814.81 \\
\hline 11 & 236820.86 & 8726296.06 & 31710.53 & 51 & 236826.6 & 8726455.03 & 31842.63 \\
\hline 12 & 236821.12 & 8726298.52 & 31710.8 & 52 & 236826.71 & 8726458.07 & 31859.29 \\
\hline 13 & 236821.49 & 8726303.21 & 31711.07 & 53 & 236826.69 & 8726461.32 & 31864.21 \\
\hline 14 & 236821.45 & 8726307.88 & 31711.32 & 54 & 236826.48 & 8726464.59 & 31858.2 \\
\hline 15 & 236821.22 & 8726312.98 & 31711.52 & 55 & 236826.34 & 8726469.07 & 31843.21 \\
\hline 16 & 236821.7 & 8726317.14 & 31711.66 & 56 & 236826.55 & 8726472.61 & 31822 \\
\hline 17 & 236822.64 & 8726322.3 & 31711.7 & 57 & 236826.38 & 8726475.77 & 31797.65 \\
\hline 18 & 236822.79 & 8726326.46 & 31711.61 & 58 & 236825.93 & 8726479.18 & 31773.14 \\
\hline 19 & 236823.27 & 8726330.62 & 31711.34 & 59 & 236826.08 & 8726482.81 & 31750.95 \\
\hline 20 & 236824.31 & 8726334.17 & 31710.87 & 60 & 236825.96 & 8726487.02 & 31732.79 \\
\hline 21 & 236825.44 & 8726338.29 & 31710.21 & 61 & 236825.56 & 8726490.7 & 31719.5 \\
\hline 22 & 236826.02 & 8726341.27 & 31709.43 & 62 & 236825.41 & 8726496.32 & 31711.13 \\
\hline 23 & 236825.99 & 8726344.29 & 31708.64 & 63 & 236825.56 & 8726500.86 & 31707.03 \\
\hline 24 & 236824.99 & 8726347.59 & 31708.11 & 64 & 236826.02 & 8726506.67 & 31706.17 \\
\hline 25 & 236824.53 & 8726351.8 & 31708.09 & 65 & 236826.32 & 8726510.17 & 31707.34 \\
\hline 26 & 236824.86 & 8726356.09 & 31708.9 & 66 & 236826.28 & 8726515.04 & 31709.42 \\
\hline 27 & 236825.25 & 8726360.44 & 31710.72 & 67 & 236826.34 & 8726519.06 & 31711.53 \\
\hline 28 & 236825.26 & 8726364.55 & 31713.55 & 68 & 236826.21 & 8726523.39 & 31713.1 \\
\hline 29 & 236824.76 & 8726368.56 & 31717.08 & 69 & 236826.32 & 8726526.89 & 31713.88 \\
\hline 30 & 236824.68 & 8726373.24 & 31720.66 & 70 & 236826.15 & 8726530.63 & 31713.91 \\
\hline 31 & 236824.79 & 8726377.26 & 31723.28 & 71 & 236826.29 & 8726535.22 & 31713.35 \\
\hline 32 & 236824.07 & 8726384.2 & 31723.7 & 72 & 236826.69 & 8726539.47 & 31712.46 \\
\hline 33 & 236824.78 & 8726387.84 & 31720.6 & 73 & 236826.93 & 8726543.16 & 31711.47 \\
\hline 34 & 236824.48 & 8726391.57 & 31712.84 & 74 & 236827.83 & 8726547.04 & 31710.54 \\
\hline 35 & 236825.31 & 8726397.45 & 31699.75 & 75 & 236828.01 & 8726553.46 & 31709.74 \\
\hline 36 & 236826.01 & 8726402.45 & 31681.37 & 76 & 236828.53 & 8726557.02 & 31709.1 \\
\hline 37 & 236826.71 & 8726408.27 & 31658.59 & 77 & 236828.6 & 8726571.75 & 31707.79 \\
\hline 38 & 236826.92 & 8726411.86 & 31633.19 & 78 & 236830.39 & 8726592.12 & 31706.34 \\
\hline 39 & 236826.84 & 8726416.49 & 31607.79 & 79 & 236834.03 & 8726619.14 & 31705.54 \\
\hline 40 & 236826.47 & 8726421.97 & 31585.45 & 80 & 236818.44 & 8726992.38 & 31702.11 \\
\hline
\end{tabular}




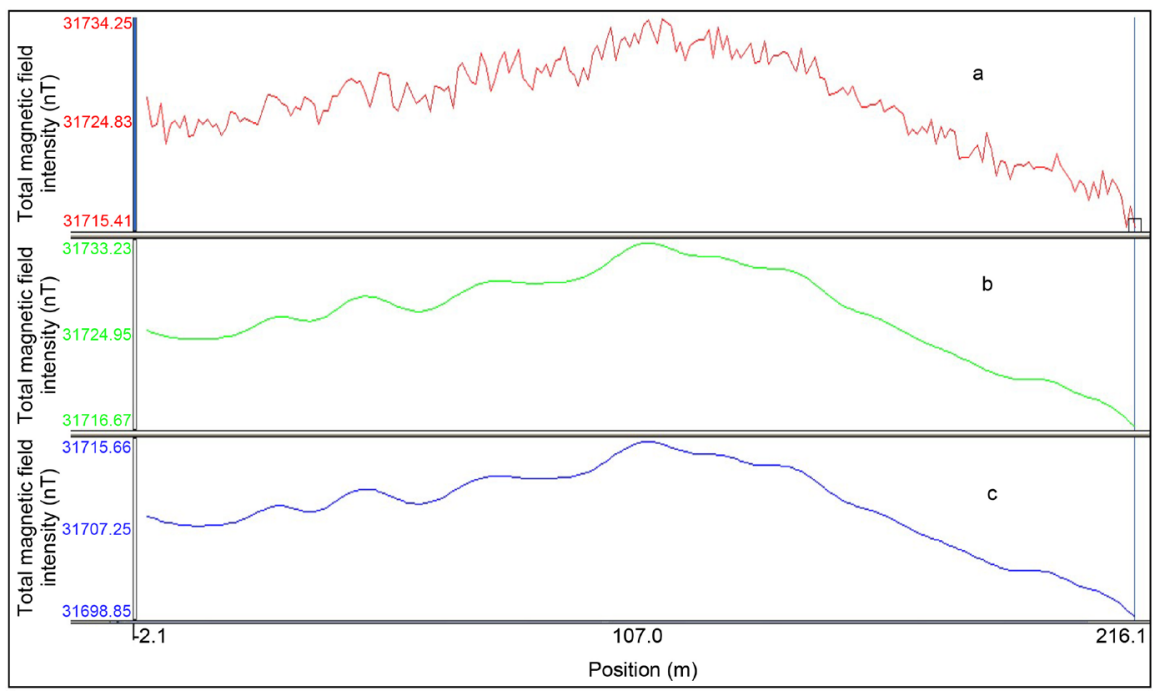

Figure 4. Profile of the data obtained by the handheld magnetometer along the line 10: (a) registration of the raw data, (b) smoothed total magnetic field, (c) corrected magnetic field.

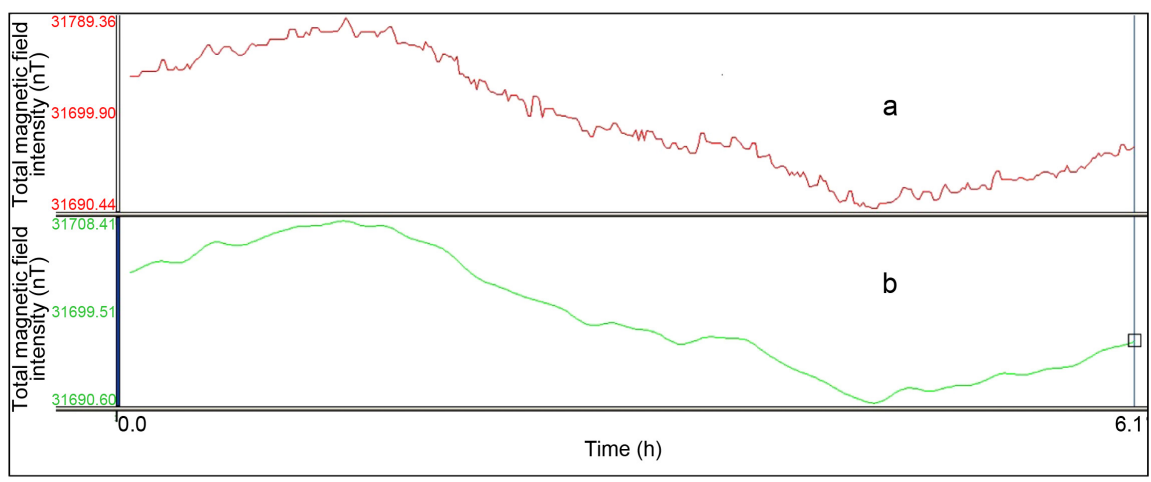

Figure 5. Profile of the diurnal variation obtained by base station, (a) registration of raw data (b) smoothed data.

$$
T=(\text { Rover }-B S)+\beta
$$

where $\beta$ is called the "datum". In this survey was considered $31,706.18 \mathrm{nT}$, which is the main value of the total magnetic field intensity observed in the study area. Due to relatively small surface surveying, the geomagnetic field (International Geomagnetic Reference Field-IGRF) was not used. The results obtained from diurnal variation correction $(T)$ in Equation (1) are used to generate the analytic signal (A), which is defined by Equation (2). This procedure allows the removal of the dipolar behavior of the total field magnetic anomaly [9].

$$
|A(x, y)|=\sqrt{\left(\frac{\partial T}{\partial x}\right)^{2}+\left(\frac{\partial T}{\partial y}\right)^{2}+\left(\frac{\partial T}{\partial z}\right)^{2}}
$$

where $\frac{\partial T}{\partial x}, \frac{\partial T}{\partial y}$ and $\frac{\partial T}{\partial z}$ are the derivatives of the total-intensity component of the magnetic field ( $T$ ) with respect to the directions $x, y$, and $z$. The advantage 
of this technique is to be a complete independence from the variation of magnetic inclination for 2D fields and the analytic signal has a high resolution [9] [10] [11]. Figure 6 illustrates the result of analytic signal applied for the line 6 (L6) through Oásis Montaj.

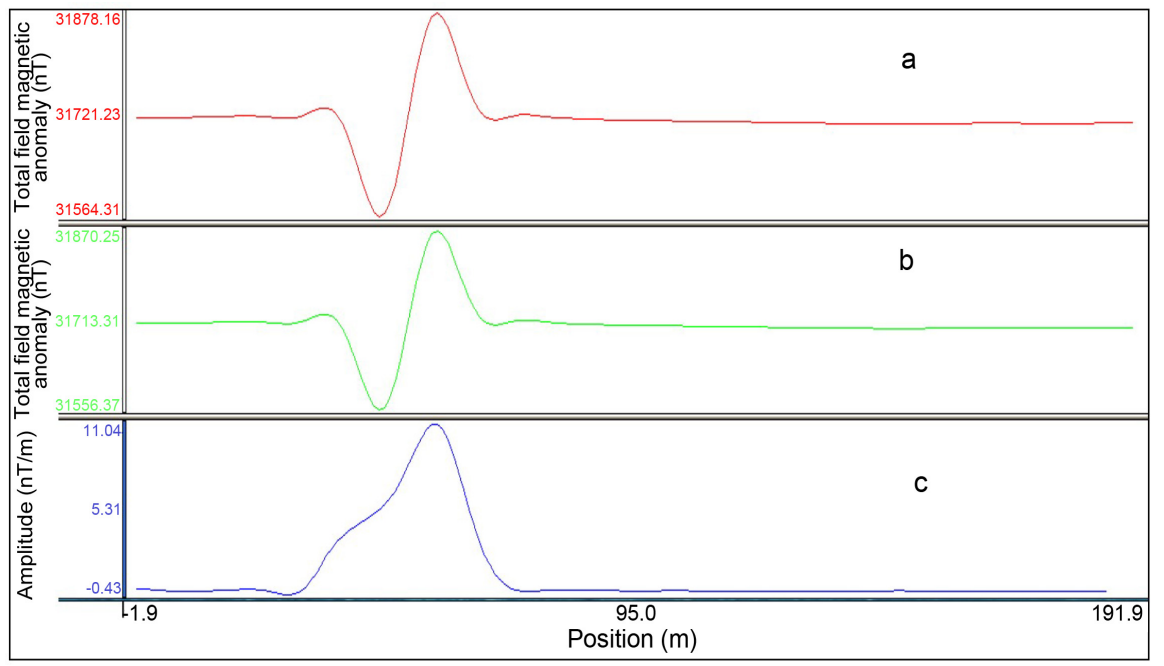

Figure 6. Profile of the data obtained by the handheld magnetometer along the line 6: (a) registration of the raw data, (b) smoothed total magnetic field, (c) the amplitude of the analytic signal calculated from the total magnetic field.

\section{Resulting and Discussion}

Table 2 shows the statistical analysis of magnetic survey measurements. Through these values, a magnetic anomaly map was created (Figure 7). The minimum value of this map was considered the statistical value and subtracted from all the values measured individually. The standard deviation was considered as the interval for the construction of this map. As a result, the area where geological materials have slightly the same magnetic characteristics were separated according to high values and low values of magnetic intensity.

\section{Qualitative and Structural Interpretation}

The Magnetic anomaly map of the total magnetic field generated from the statistical analysis is roughly divided into two separate areas. The first area is located in the Northeast part of the map (Figure 7), which consists of geological materials that have magnetic values below $100 \mathrm{nT}$ and the second area, which covers most of the survey containing geological materials associated with magnetic values above $100 \mathrm{nT}$ (Figure 7). In addition, there is a structure with SWW-NEE directions in which magnetic signatures that indicate the presence of kimberlite pipes are observed. Four magnetic dipoles are present in the structure where high magnetic values are located in the north of the low magnetic values. The high magnetic pole in anomaly $\mathrm{D}$, however, is not observed. This occurs due to the interpolator (kriging) used for the generation of this map.

Total magnetic field intensity illustrated in Figure 8 shows the high values of 


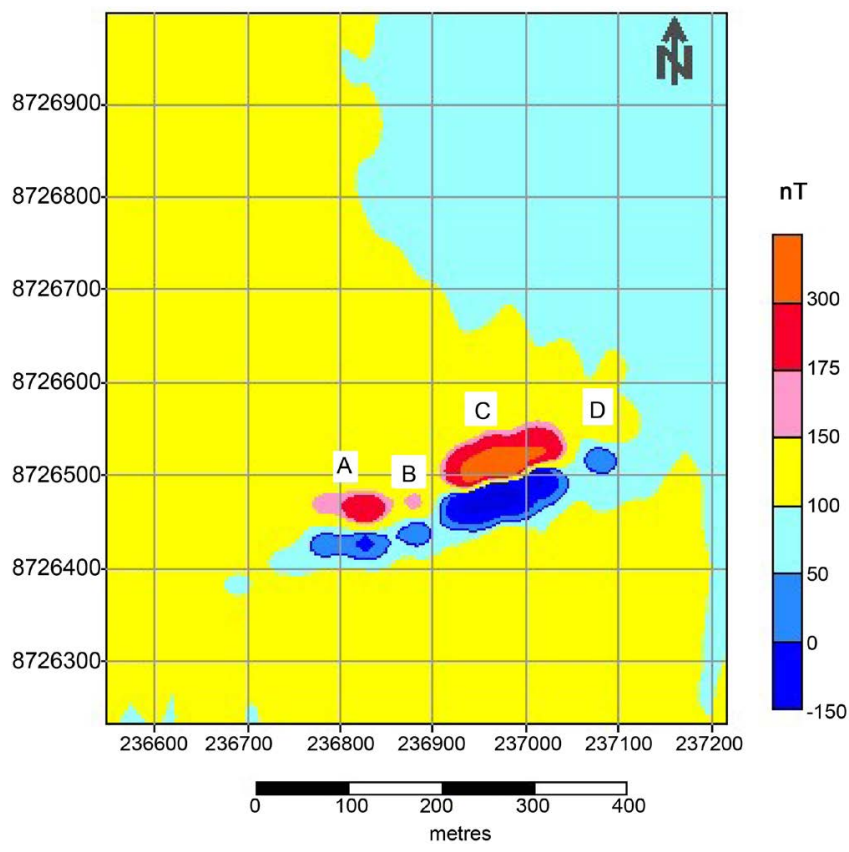

Figure 7. Magnetic anomaly map of study area through statistical analyses, showing the four magnetic anomalies related to Kimberlite pipes.

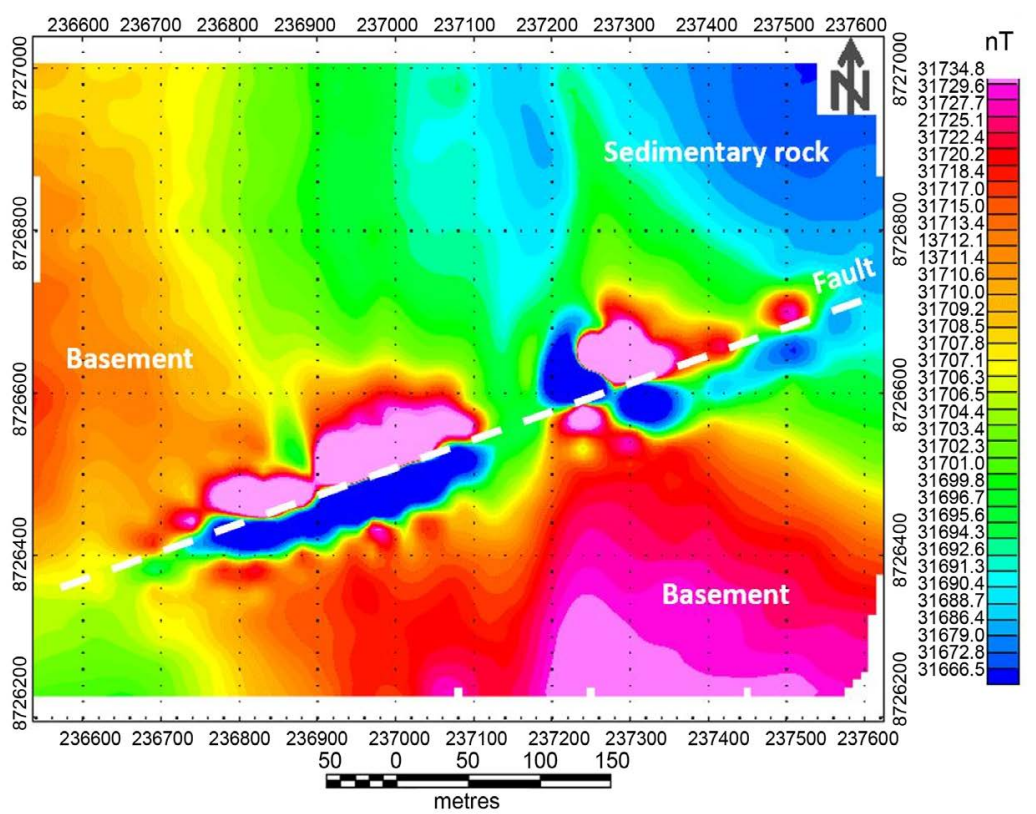

Figure 8. Observed total magnetic field intensity over the Luando, Bié.

Table 2. Statistical analysis of total magnetic field Intensity.

\begin{tabular}{cc}
\hline Statistical Parameters & \\
\hline Observed data & 2744 \\
Minimum value & $31186.93 \mathrm{nT}$ \\
Maximum value & $32141.4 \mathrm{nT}$ \\
Arithmetic mean & $31706.18 \mathrm{nT}$ \\
Standard deviation & $48.0374 \mathrm{nT}$
\end{tabular}


the total magnetic field associated with the geological materials, which are identified in the south and west part of the study area. While the Northeast part of this map is covered by geological materials whose values the total magnetic field are relatively low when compared to those located in south or west part. A fault in this map was observed with SW-NE directions in which rest the magnetic signatures associated with the kimberlites (Figure 8). This suggests that the kimberlites have risen due to this fault. The fault sinks towards the NEE direction where the embedding rock is at great depths. Consequently, it presents an extremely thick sediment cover, which justifies the low values of magnetic field intensity presented. However, this pattern is no longer observed in the south and west area, where there are high values of the magnetic field intensity justified by the presence at low depths of crystalline rocks.

As the study area is located relatively at low latitude, there is a clear advantage using the analytical signal of the total magnetic field [4]. Therefore, the analytical signal in Figure 9 calculated from the original total magnetic field data as a practical alternative to reduction to the pole [9] [12] [13] shows the four magnetic anomalies associated with kimberlite pipes. All of these anomalies have a strong analytic signal response. This technique is one of the methods used to identify kimberlite magnetic anomalies [4]. The kimberlite magnetic signatures (Figure 9) are associated with tabular and circular anomalies, observed in A and $\mathrm{B}$, and $\mathrm{C}$ and $\mathrm{D}$ respectively. Their area varies approximately from $1257 \mathrm{~m}^{2}$ to $10,956 \mathrm{~m}^{2}$. The analytical signal map also shows exactly the fault orientation identified previously through Magnetic anomaly map.

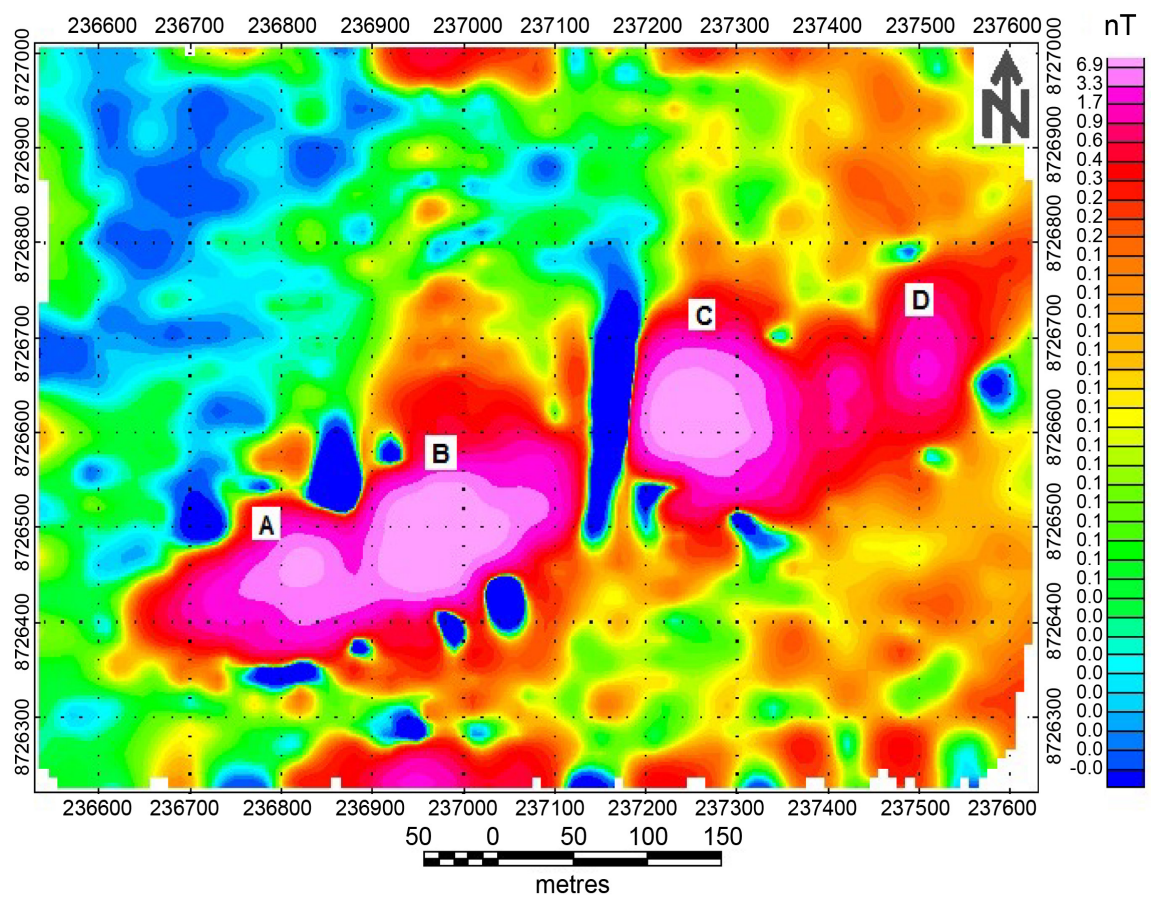

Figure 9. The amplitude of the analytic signal calculated from the total magnetic field shown in Figure 8. 


\section{Conclusions}

This paper shows a typical procedure used for near-surface geophysical study in Luando area for the identification of magnetic anomalies due to kimberlite pipes. Three different magnetic maps are obtained from the result of total magnetic field data processing. Interpretation of the magnetic anomalies of total magnetic field data is a complicated process due to their dipolar nature [11]. Because of this, the analytic signal is generated. Thus, the main results of this study are:

1) The interpretation through the map of total magnetic field intensity correlates correctly with the generated map from the statistical analysis. In both maps, two distinguished areas are observed, one with high magnetic values and the other with low magnetic values.

2) It is possible to identify with great accuracy in these maps four magnetic signatures that can be associated with kimberlite pipes. These anomalies are found in the main structure linked by the fault with SWW-NEE directions. Moreover, in this study area is noted that all magnetic anomalies associated with kimberlite pipes are found in topographic lows.

3) The application of analytic signal technique allowed the complete removal of the four dipolar anomalies presented in the total magnetic field map, placing its maximum amplitude toward the barycentre of the anomaly sources. As a result, two distinctive shapes of a magnetic anomaly due to kimberlite pipes are observed, which are tabular and circular with very strong amplitude of the analytical signal.

\section{Acknowledgements}

The authors thank mineral society SOMIPA for providing all logistics for carrying out this Geophysical survey. Thanks to all academic staff of the Department of Geosciences at ISPTEC for encouraging research.

\section{Conflicts of Interest}

The authors declare no conflicts of interest regarding the publication of this paper.

\section{References}

[1] Hinze, W.J., Von Frese, R.R.B. and Saad, A.H. (2012) Gravity and Magnetic Exploration Principles, Practices, and Applications. Cambridge University Press, England, 231-232.

[2] Burger, H.R., Sheehan, A.F. and Jones, C.H. (2006) Introduction to Applied Geophysics: Exploring the Shallow Subsurface, W.W. Norton \& Company, New York, 429-497.

[3] Brummer, J.J., Macfadyen, D.A. and Pegg, C.C. (1992) Discovery of Kimberlites in the Kirkland Lake Area, Northern Ontario, Canada; Part II: Kimberlite Discoveries, Sampling, Diamond Content, Ages and Emplacement. Exploration and Mining Geology, 1, 351-370. 
[4] Keating P. and Sailhac P. (2004) Use of the Analytic Signal to Identify Magnetic Anomalies Due to Kimberlite Pipes. Society of Exploration Geophysicists, 69,180. https://doi.org/10.1190/1.1649386

[5] Brummer, J.J. (1978) Diamonds in Canada. Canadian Mining and Metallurgy Bulletin, 71, 64-79.

[6] Araújo, A.G. and Guimarães, F. (1992) Geology of Angola. Noticia Explicativa da Carta Geológica à Escala 1:1000000, Luanda, Angola.

[7] Araújo A.G., Perevalov, O.V., et al. (1998) Carta de Recursos Minerais da República de Angola.

[8] Mejelovssky, N.V. (1986) Carta Cosmogeodinâmica de Angola. Escala 1:2000000. Serviço Geológico de Angola. Ministério de Geologia e Minas. (Tectonic setting fonte).

[9] Nabighian, M.N. (1972) The Analytic Signal of Two-Dimensional Magnetic Bodies with Polygonal Cross-Section: Its Properties and Use for Automated Anomaly Interpretation. Geophysics, 37, 507-517. https://doi.org/10.1190/1.1440276

[10] Milano M. and Fedi, M. (2014) Analytic Signal and Magnetic Field Moduli Analysis in Europe. Università degli Studi Federico II di Napoli, Italy. GNGTS. Sessione 3.2.

[11] Ansari A.H. and Alamdar K. (2009) Reduction to the Pole of Magnetic Anomalies Using Analytic Signal. World Applied Sciences Journal, 7, 405-409.

[12] Roest, W.E., Verhoef, J. and Pilkington, M. (1992) Magnetic Interpretation Using 3-D Analytic Signal. Geophysics, 57, 116-125. https://doi.org/10.1190/1.1443174

[13] Macleod, I.N., Vierra, S. and Chaves, A.C. (1993) Analytic Signal and Reduction-to-the-Pole in the Interpretation of Total Magnetic Field Data at Low Magnetic Latitudes. Proceedings of the Third International Congress of the Brazilian Society of Geophysicists, Rio de Janeiro, Brazil, 7-11 November.

https://doi.org/10.3997/2214-4609-pdb.324.830 